\title{
Loss of RIPK3 does not impact MYC-driven lymphomagenesis or chemotherapeutic drug-induced killing of malignant lymphoma cells
}

\author{
Rachel Thijssen ${ }^{1,2} \cdot$ Silvia Alvarez-Diaz ${ }^{1,2} \cdot$ Clea Grace $^{1,3} \cdot$ Ming-yuan Gao ${ }^{1,2} \cdot$ David H. Segal ${ }^{1,2} \cdot$ Zhen Xu $^{1,2} \cdot$ \\ Andreas Strasser ${ }^{1,2} \cdot$ David C. S. Huang $\mathbb{B I}^{1,2}$
}

Received: 8 December 2019 / Revised: 4 June 2020 / Accepted: 5 June 2020 / Published online: 18 June 2020

(c) The Author(s) 2020. This article is published with open access

Several studies have shown that loss of expression of the receptor-interacting serine/threonine protein kinase 3 (RIPK3), an essential mediator of necroptotic cell death, promotes the development of cancer, including acute myeloid leukaemia [1]. Moreover, downregulation of RIPK3 has been associated with the resistance of chronic lymphocytic leukaemia cells to necroptotic cell death [1]. Here, we studied the impact of loss of RIPK3 in a mouse model of MYC-driven lymphomagenesis and on the killing of malignant lymphoma cells induced by chemotherapeutics. We found that Ripk3 deficiency did not accelerate lymphoma development in $E \mu-M y c$ transgenic mice. Moreover, the loss of RIPK3 did not alter the sensitivity of $E \mu-M y c$ lymphoma cells to chemotherapeutic drugs. These results reveal that RIPK3 does not play critical roles for the development of MYC-driven lymphomas or their therapeutic responses.

To examine the impact of the loss of Ripk3 on MYCdriven lymphomagenesis, we utilised the $E \mu-M y c$ mouse

These authors contributed equally: Rachel Thijssen, Silvia AlvarezDiaz

Supplementary information The online version of this article (https:// doi.org/10.1038/s41418-020-0576-2) contains supplementary material, which is available to authorised users.

Andreas Strasser

strasser@wehi.edu.au

$\triangle$ David C. S. Huang

huang_d@wehi.edu.au

1 The Walter and Eliza Hall Institute of Medical Research, Parkville, VIC 3052, Australia

2 Department of Medical Biology, University of Melbourne, Parkville, VIC 3050, Australia

3 Present address: St Vincent's Institute of Medical Research, Fitzroy, VIC 3065, Australia model. E $\mu-M y c ; R i p k 3^{-/-}$mice displayed a median survival of 97 days $(n=80)$, which was not significantly different from the 118 days seen in control $E \mu-M y c$ mice $(n=37)$ $\left(E \mu-M y c ; R i p k 3^{-l-}\right.$ vs $E \mu-M y c$ mice, $\left.p=0.0944\right)$ (Fig. 1a). At the ethically mandated endpoint, the severity of disease, as determined by the extent of spleen and lymph node enlargement and white blood cell counts, was comparable between mice of the two genotypes (Supplementary Fig. 1a, b). Immuno-phenotyping revealed that all lymphomas in $E \mu-M y c ; R_{i p k 3^{-1-}}$ mice were, as expected, of pro/pre-B $\left(\mathrm{B} 220^{+} \mathrm{sIg}^{-}\right)$or $\mathrm{B}\left(\mathrm{B} 220^{+} \mathrm{sIg}^{+}\right)$origin, although there was an increased portion of mixed pre-B/B lymphomas compared with the control $E \mu-M y c$ mice (Fig. 1b).

Some other studies have reported that treatment with chemotherapeutic drugs induces the formation of the RIPK1/RIPK3/CASPASE-8 ripoptosome complex that triggers necroptotic cell death and that knockdown of RIPK3 can inhibit this killing of tumour cells [2-6]. To assess whether loss of RIPK 3 could affect the response of malignant lymphoma cells to therapeutic agents we made use of CRISPR/Cas9 technology to generate $E \mu$-Myc p53 wild-type (AF47A and AH15A) lymphoma cell lines that are deficient for RIPK3 (Supplementary Fig. 2a, b). The Ripk3 knockout cells showed similar sensitivity to etoposide, paclitaxel or dexamethasone as the control cells, although some minor differences were observed (Fig. 1c-e). Similarly, the loss of RIPK3 had no impact on the response of lung carcinoma, colon carcinoma or thymic lymphoma derived cell lines to a range of chemotherapeutics [7, 8]. Human and mouse tumour cells driven by deregulated over-expression of c-MYC are highly dependent on the anti-apoptotic protein MCL-1 for survival and the MCL-1-specific BH3 mimetic drug S63845 induces dose dependent apoptotic death in murine $E \mu-M y c$ as well as human Burkitt's lymphoma cell lines [9, 10]. Loss of RIPK3 did not affect the response of 

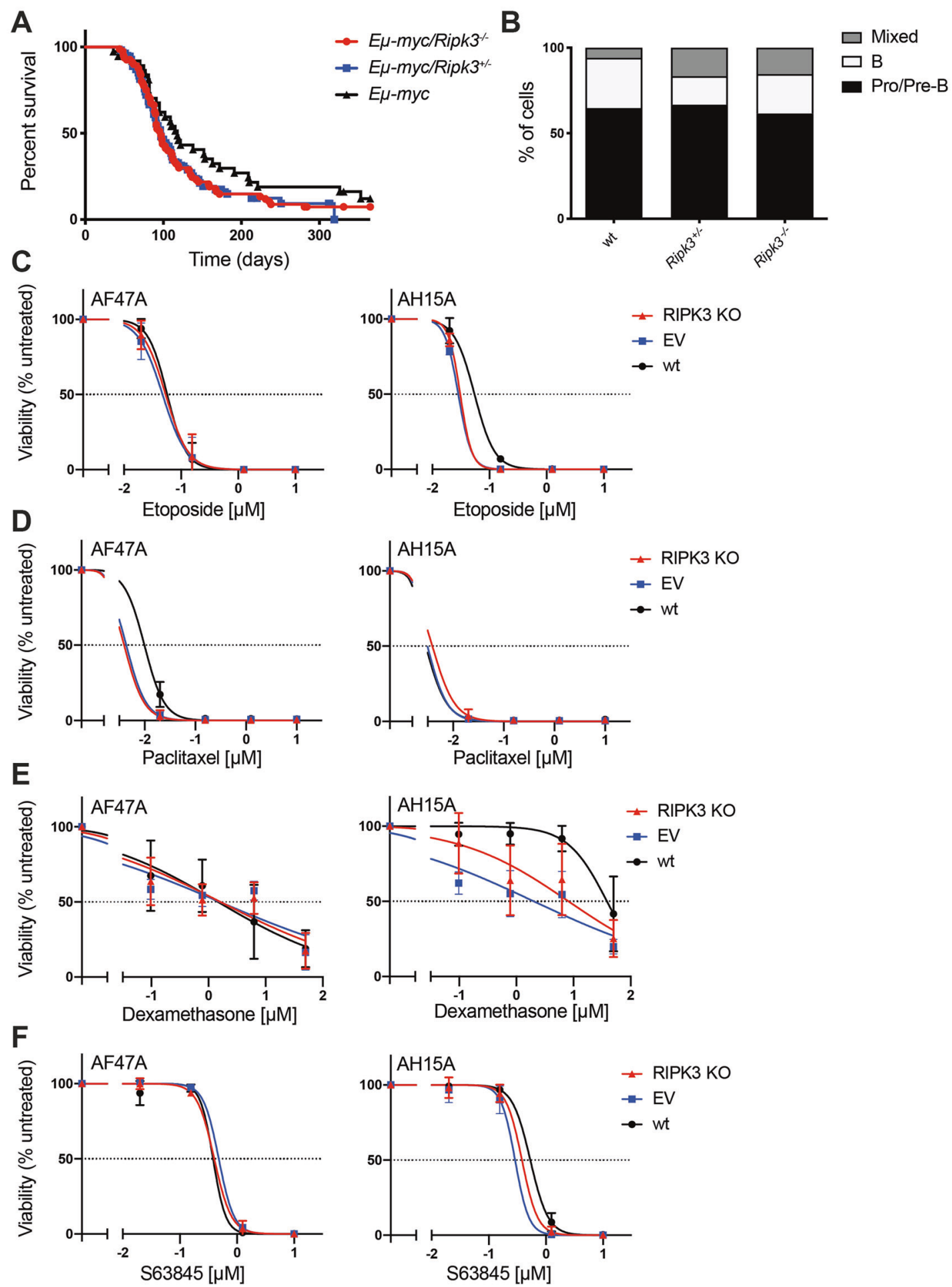

Fig. 1 RIPK3 does not play a critical role in the development or therapeutic response in MYC-driven lymphomas. a Kaplan-Meier survival curves of $E \mu-M y c$ ( $n=37$, median survival of 118 days), $E \mu-M y c ; R_{i p k} 3^{+-}(n=54$, median survival of 97 days $)$ or E $\mu-M y c$; $\operatorname{Ripk}^{-I-}(n=80$, median survival of 97 days) mice. The difference in survival between mice of the different the genotypes was not significant (log-rank (Mantel-Cox) test). b Stacked bar graph showing the percentages of pro/pre-B (B220 $\left.{ }^{+} \mathrm{sIg}^{-}\right)$, B (B220+ $\left.\mathrm{sIg}^{+}\right)$and mixed pre$\mathrm{B} / \mathrm{B}$ cell lymphomas observed for $E \mu-M y c(n=34), E \mu-M y c ; R i p k 3^{+/-}$ $(n=6)$ and $E \mu-M y c ; R_{i p k} 3^{-1-}(n=13)$. The difference in surface marker phenotype between lymphomas of the different genotypes was not significant (repeated measures one-way ANOVA, with the Geisser-Greenhouse correction). c-f $E \mu$ - $M y c$ lymphoma cell lines with wt $p 53, \mathrm{AF} 47 \mathrm{~A}$ and $\mathrm{AH} 15 \mathrm{~A}$, transduced with expression constructs for Cas9 and sgRNAs targeting Ripk3 (RIPK3 KO) or transduced with an empty vector $(\mathrm{EV})$ were treated with increasing concentrations of etoposide $(0-10 \mu \mathrm{M})(\mathbf{c})$, paclitaxel $(0-10 \mu \mathrm{M})(\mathbf{d})$, dexamethasone $(0-50 \mu \mathrm{M})(\mathbf{e})$ for $48 \mathrm{~h}$, or (f) with S63845 $(0-10 \mu \mathrm{M})$ for $24 \mathrm{~h}$. Cell viability was assessed using Annexin V plus PI staining and FACS analysis. The frequency of Annexin $\mathrm{V}^{-} \mathrm{PI}^{-}$cells was normalised to control (DMSO treated) cells (Viability (\% untreated)). Means \pm SD for three independent experiments are shown. 
$E \mu$-Myc lymphoma cell lines to S63845 (Fig. 1f). Staining with Annexin V and propidium iodide (PI) revealed that both the parental and the Ripk3-deleted E $\mu$-Myc lymphoma cells showed classical features of apoptosis (Annexin $\mathrm{V}^{+} \mathrm{PI}^{-}$) at early time points after treatment with chemotherapeutic drugs (Supplementary Fig. 3). Accordingly, loss of the pro-apoptotic effectors BAX and BAK rendered the $E \mu-M y c$ lymphoma cells completely resistant to these agents (Supplementary Fig. 3).

Collectively, these findings demonstrate that RIPK3, and by extension necroptotic cell death, is not a major suppressor of MYC-driven lymphoma development. Moreover, the results indicate that RIPK3 and necroptosis do not play major roles in the response of malignant lymphoma cells to a range of anti-cancer agents, at least under tissue culture conditions. As the $E \mu-M y c$ mice constitute a model of human Burkitt's lymphoma, it therefore remains possible that RIPK3 and necroptosis may play a role in other types of lymphoma or other malignancies. Moreover, RIPK3 and necroptosis might play a role in the response of $E \mu-M y c$ lymphomas (and other tumours) to anti-cancer agents in vivo, perhaps by impacting anti-tumour immune responses from the host, and we will make our cell lines available for such investigations.

Acknowledgements This work was supported by grants and fellowships from the Australian National Health and Medical Research Council (programme grant no. 1016701, Senior Principal Research Fellowship 1020363 to AS and Principal Research Fellowship 1156024 to DCSH), the Leukemia \& Lymphoma Society of America (Fellowship 5467-18 to RT and Specialized Center of Research grants no. 7001-13 and 7015-18 to AS and DCSH), a Spanish Ministry of Education Postdoctoral Fellowship to SA-D, a Cancer Australia and Cure Cancer PdCCRS grant 1186003 to RT, an Australian Government Research Training Program Scholarship to CG, as well as by operational infrastructure grants through the Australian Government Independent Research Institute Infrastructure Support Scheme and the Victorian State Government Operational Infrastructure Support Program.

\section{Compliance with ethical standards}

Conflict of interest The authors declare that they have no conflict of interest.

Publisher's note Springer Nature remains neutral with regard to jurisdictional claims in published maps and institutional affiliations.
Open Access This article is licensed under a Creative Commons Attribution 4.0 International License, which permits use, sharing, adaptation, distribution and reproduction in any medium or format, as long as you give appropriate credit to the original author(s) and the source, provide a link to the Creative Commons license, and indicate if changes were made. The images or other third party material in this article are included in the article's Creative Commons license, unless indicated otherwise in a credit line to the material. If material is not included in the article's Creative Commons license and your intended use is not permitted by statutory regulation or exceeds the permitted use, you will need to obtain permission directly from the copyright holder. To view a copy of this license, visit http://creativecommons. org/licenses/by/4.0/.

\section{References}

1. Huang X, Xiao F, Li Y, Qian W, Ding W, Ye X. Bypassing drug resistance by triggering necroptosis: recent advances in mechanisms and its therapeutic exploitation in leukemia. J Exp Clin Cancer Res. 2018;37:310.

2. Tenev T, Bianchi K, Darding M, Broemer M, Langlais C, Wallberg F, et al. The Ripoptosome, a signaling platform that assembles in response to genotoxic stress and loss of IAPs. Mol Cell. 2011;43:432-48.

3. Jang MS, Lee SJ, Kang NS, Kim E. Cooperative phosphorylation of FADD by Aur-A and Plk1 in response to taxol triggers both apoptotic and necrotic cell death. Cancer Res. 2011;71:7207-15.

4. Brown MF, Leibowitz BJ, Chen D, He K, Zou F, Sobol RW, et al. Loss of caspase-3 sensitizes colon cancer cells to genotoxic stress via RIP1-dependent necrosis. Cell Death Dis. 2015;6:e1729.

5. Koo GB, Morgan MJ, Lee DG, Kim WJ, Yoon JH, Koo JS, et al. Methylation-dependent loss of RIP3 expression in cancer represses programmed necrosis in response to chemotherapeutics. Cell Res. 2015;25:707-25.

6. Xu Y, Lin Z, Zhao N, Zhou L, Liu F, Cichacz Z, et al. Receptor interactive protein kinase 3 promotes cisplatin-triggered necrosis in apoptosis-resistant esophageal squamous cell carcinoma cells. PLoS ONE. 2014;9:e100127.

7. Yang H, Ma Y, Chen G, Zhou H, Yamazaki T, Klein C, et al. Contribution of RIP3 and MLKL to immunogenic cell death signaling in cancer chemotherapy. Oncoimmunology. 2016;5: e1149673.

8. Moriwaki K, Bertin J, Gough PJ, Orlowski GM, Chan FK. Differential roles of RIPK1 and RIPK3 in TNF-induced necroptosis and chemotherapeutic agent-induced cell death. Cell Death Dis. 2015;6:e1636.

9. Kelly GL, Grabow S, Glaser SP, Fitzsimmons L, Aubrey BJ, Okamoto T, et al. Targeting of MCL-1 kills MYC-driven mouse and human lymphomas even when they bear mutations in p53. Genes Dev. 2014;28:58-70.

10. Kotschy A, Szlavik Z, Murray J, Davidson J, Maragno AL, Le Toumelin-Braizat G, et al. The MCL1 inhibitor S63845 is tolerable and effective in diverse cancer models. Nature. 2016;538: 477-82. 